\title{
EL APRENDIZAJE DE ALGUNOS CONCEPTOS FUNDAMENTALES EN EL CAMPO DE LA BOTANICA. UNA EXPERIENCIA INVESTIGACIÓN AULA
}

\author{
Eblis Álvarez Salgado* \\ Humberto Arias Guevara*
}

\begin{abstract}
Colombia is a "mega diversity" country about his flora, for that reason we consider fundamental to perform works related with the learning in botany.

This matter is very important, because the works in history botany has been realized by professionals without pedagogic formation and in some cases without formation in plant subject.

There are not many works in pedagogic and didactic about the conceptual learning in botany, we emphasize the need of design, apply and value methodologies strategies that allows to approach basic concepts in that subject, this is the main matter in this investigation line according the constructivism tendency
\end{abstract}

\section{PALABRA CLAVES}

Aprendizaje - botánica - investigación -aula - constructivismo - estrategias.

\section{INTRODUCCIÓN}

Ante la creciente destrucción de los Ecosistemas y dado, que la diversidad biológica es la base de nuestra vida diaria, en la actualidad se hace mucho énfasis en el estudio de la Biodiversidad, la cual puede ser entendida como La variación de las formas de vida, manifestada en la diversidad genética, de poblaciones, especies, ecosistemas, paisajes", (Departamento de Planeación 1997) que también podría incluir manifestaciones culturales.

Cuando se examina la biodiversidad mundial, se encuentra que Colombia es considerado como uno de los países megadiverso, en donde su flora se calcula con una riqueza aproximada entre 45.000 - 50.000 especies de plantas, número elevado en relación con su área (Caballero 1995).

\footnotetext{
${ }^{*}$ Profesor titular Universidad Pedagógica Nacional.

${ }^{* *}$ Profesor titular Universidad Distrital 


\section{JUSTIFICACIÓN}

Los vegetales son considerados como parte integral de nuestro ambiente y en forma más específica como los productores en los Ecosistemas, por lo tanto es imperativo para el hombre, el estudio y conocimiento de estos organismos con fines de preservación y utilización racional dentro del concepto de desarrollo sostenible

Podemos decir que el interés por la Botánica en Colombia se inicia con los aborígenes, quiénes antes de la llegada de los Españoles ya cultivaban maíz, varios tipos de tubérculos y raíces (Díaz 1991).

En la época Colonial es importante destacar a Mutis y su Obra, la Expedición Botánica, la cual marcó un hito en la historia de nuestro país con variadas consecuencias (Díaz 1991).

En lo referente el estudio y enseñanza de los vegetales en Colombia históricamente, ha sido realizado por profesionales especializados solamente en el Campo de la Botánica, sin formación profesional en pedagogía, haciendo énfasis inicialmente en lo descriptivo y muy recientemente en lo fisiológico y molecular, con tendencia transmisionista.

En consideración a lo anterior y motivados por la ausencia de trabajo de carácter pedagógico y didáctico en el aprendizaje conceptual de la botánica y fundamentados en la tendencia constructivista, hemos propuesto y ejecutado en parte una línea de investigación-aula relacionada con el aprendizaje significativo (Ausubel et al 1983) de algunos conceptos fundamentales de botánica.

\section{OBJETIVOS}

- Proponer una forma general de trabajo en el Aprendizaje Significativo de algunos conceptos botánicos, basados en nuestra experiencia como docentes en ese campo.

- Diagnosticar la situación actual de la enseñanza de la botánica a nivel de educación básica secundaria

- Revisar la forma como se ha desarrollado la enseñanza y el aprendizaje en botánica, tanto a nivel nacional como internacional.

- Diseñar, aplicar y evaluar algunas estrategias metodológicas para abordar conceptos estructurantes en la Botánica.

- Divulgar los resultados obtenidos en el desarrollo de la línea de investigación.

\section{LOGROS}

Como parte de los resultados obtenidos en la línea de investigación, cabe destacar algunos escritos, tales como: 
"Algunas consideraciones generales sobre el aprendizaje conceptual en botánica, (ALVAREZ y ARIAS 1996), en donde se pretende, hacer una reflexión sobre una forma de realizar trabajos de aprendizaje en Botánica, retomando nuestra experiencia como docentes en dicho campo Consideramos que este trabajo conceptual debe incluir tres niveles:

Uno de carácter descriptivo del objeto de estudio, así como también la respectiva caracterización del ambiente.

Un segundo nivel que permita la posibilidad de caracterización del objeto con ayuda de microscopio y aplicación de técnicas.

Un tercer nivel estaría relacionado con la inclusión de aspectos físico-químicos, ya que trabajamos con estructuras que presentan una determinada composición química y cumplen una función, para así abordando así el concepto en cuestión, en forma interdisciplinaria.

Como aspecto final del trabajo en mención, debemos examinar las posibles formas de aplicación del trabajo conceptual incluyendo también el afianzamiento en valores, y el desarrollo de habilidades y destrezas para lograr una forma integral de construcción conceptual.

En el articulo, "Una forma de abordar el concepto briofita (ALVAREZ y ARIAS 1997), se resalta que ante la ausencia de trabajos de carácter pedagógico y didáctica en el aprendizaje conceptual de la Botánica se, proponemos una estrategia para abordar el concepto briofita, fundamentados en la tendencia constructivista.

La estrategia anterior, comprende varias fases: diagnosticar predisposición hacia el trabajo constructivista; actividades de campo relacionadas con la caracterización del ambiente y de la forma externa del objeto de estudio. La labor anterior se complementa con prácticas de laboratorio, para ampliar y precisar información acerca del grupo de organismos en estudio; la cual deberá ser reportada en forma escrita y posteriormente socializada y negociada. Como parte fundamental en esta metodología se incluye el planteamiento y resolución de problemáticas.

Con posibilidades de publicación se han enviado los escritos:

"Aplicación del mapa conceptual en la evaluación del Aprendizaje del concepto semilla", enfatizándose en el escrito, que de las diversas formas de evaluación de aprendizajes, una de las más recientes correspondiente a los mapas conceptuales, se utilizó para detectar el grado de aprendizaje significativo del concepto semilla.

Esta herramienta se aplicó a estudiantes de un curso de vegetales del programa de Licenciatura en Biología, solicitando a elaboración de un mapa inicial y luego final este ultimo después de aplicada la estrategia de trabajo.

Al examinarse evaluaron los mapas elaborados por los estudiantes, encontrándose muchas deficiencias en el inicial y una notable mejoría tanto en jerarquización, interrelaciones y el uso de conectores, en el campo final. 
En general se notó un grado de avance en los estudiantes en la construcción del concepto semilla.

Cabe también mencionar el articulo Algunos antecedentes sobre el aprendizaje y la enseñanza en Botánica" escrito que pretende mostrar algunos antecedentes sobre el trabajo en Botánica, desde sus inicios hasta el presente, resaltando las realizaciones de diferentes botánicos a nivel mundial y nacional. También se muestran los desarrollos académicos en los diferentes niveles de la enseñanza de la Botánica, destacándose que para este aspecto es pobre el énfasis en lo didáctico y metodológico, ya que esta enseñanza se ha orientado mayormente para actividades trabajos de carácter transmisionista.

Otro trabajo importante es el titulado "Una propuesta hacia el aprendizaje significativo del concepto propagación natural de una manera integral”, que considera que para una labor didáctico dentro del marco constructivista, donde el sujeto es el actor principal, es fundamental indagar en los estudiantes el grado de autonomía, autoestima, capacidad de socialización y negociación de saberes. Estas características personales del estudiante que pueden examinarse mediante la aplicación de un instrumento que diagnostique el ambiente psicosocial, denominado CLES (Constructivist Learning Environment Survey) de Taylor y Fraser citado por Ritchie (1994), que diagnostique el ambiente psicosocial para el aprendizaje conceptual

La propuesta contempla como aspecto fundamental la resolución de problemas, lo que podría permitir que el estudiante sea el protagonista activo de su propio aprendizaje y que si no es capaz de generar autogestión, muy probablemente se deba a la carencia de autonomía en el trabajo, lo cual minaría su capacidad en el quehacer, por lo tanto mostraría baja autoestima, y pocas posibilidades debatir información no podría asumir un rol en las actividades de socialización y negociación de saberes. Estos planteamientos se aproximan a las consideraciones de Vigoskty en su propuesta de la llamada zona de desarrollo próximo "citado por Martin (1992)".

Actualmente se encuentra en revisión el artículo "Diagnóstico del estado actual de la Enseñanza en Botánica en básica secundaría", en el cual se plantea una reflexión sobre la importancia de los estudios en Botánica que conlleve a la consideración de valores, procedimientos y conocimientos, en especial al respeto de todas las formas de vida y a la concientización que el aprendizaje en ciencias tienda a que la información sea necesaria, útil y relevante con el fin de formar un ciudadano integral con una mejor calidad de vida.

Conscientes de esta problemática y en nuestro carácter de formadores de docentes en el campo de la Botánica, debemos conocer la realidad de cómo se está realizando este trabajo a nivel de la básica secundaria, para ello diseñamos y aplicamos un instrumento exploratorio acerca de aspectos básicos tales como "nivel académico del docente; énfasis temático en o cognitivo su utilidad y aplicación estrategias de trabajo en su quehacer docente instrumentos y formas de evaluación fuentes bibliográficas utilizadas. Este instrumento fue aplicado a 20 maestros de diferentes Instituciones públicas y privadas edad, experiencia docente, sexo, nivel académico.

Como aspecto relevante de este trabajo, destacamos que los maestros expresan aplicar la tendencia constructivista, lo cual puede considerarse a nuestro juicio un aspecto positivo, más sin embargo se muestran algunas contradicciones cuando se les indaga sobre aspectos fundamentales del trabajo constructivista 
Como parte del desarrollo de la línea, se han consolidado cuatro trabajos de grado de los cuales tres se han culminado y hay uno en ejecución. Esta serie de trabajos se ha centrado, en el diseño, aplicación y evaluación de estrategias metodológicas en la construcción conceptual, encontrándose, que cuando se aplica la tendencia constructivista se ha logrado un mejoramiento en el aprendizaje significativo de algunos conceptos en botánica.

Debemos resaltar como un gran logro la revisión y ejecución de formas de trabajo de nuestro quehacer docente en el VI semestre en el campo de los vegetales, además de la posibilidad de interactuar como pares

Esperamos con estos logros llamar la atención sobre la necesidad de revisar, por parte de los docentes, la importancia y forma de trabajo conceptual en Botánica, proponiendo algunas alternativas didácticas del quehacer docente en el aula y fuera de ella, haciendo énfasis en la formación integral del estudiante como futuros educadores

\section{BIBLIOGRAFÍA}

ALVAREZ. E. y ARIAS, H. 1996 Algunas consideraciones generales sobre el aprendizaje conceptual en Botánica Revista Estudios en Pedagogía y Didáctica Bogotá. Vol. 1. № 1

ALVAREZ, E y ARIAS. H 1997. Una forma de abordar el concepto Briofita. Revista Estudios en Pedagogía y Didáctica, Bogotá, Vol 2 No. 1.

AUSUBEL, et al 1993. Psicología Educativa: Un punto de vista cognoscitivo. Editorial Trillas-México.

CABALLERO, R 1995. La Etnobotánica en comunidades negras e indígenas del delta del río Patía". 1ª Edición Editorial Akya-Yala. Quito.

DEPARTAMETNO NACIONAL DE PLANEACIÓN (Colombia), 1997. Política nacional de biodiversidad. Bogotá.

DÍAZ, S. 1991. La botánica en Colombia, hechos notables en su desarrollo. Revista académica de ciencias exactas físicas y naturales, Santafé de Bogotá.

MARTIN, E. 1992. La fundamentación psicológica del currículum de la reforma educativa. En MARTIN, E. y FERRANDIS, A. Fundamentaciones psicológicas y sociológicas del diseño curricular base. Educación Abierta, Instituto de Ciencias de la Educación de la Universidad de Zaragosa. Zaragosa.

RITCHIE, S. M. 1994. Metaphor as a tool for constructivist science teach. In Journals Science Education. Vol. 16, No. 3. 